\title{
PEQUENAS CIDADES E ESPECIALIZAÇÕES FUNCIONAIS: O CASO DE SANTA FÉ - PR
}

\section{Small cities and functional specialization: The case of Santa Fé - Pr}

Tânia Maria Fresca

Prof $^{\mathrm{a}}$ Associada da Universidade Estadual de Londrina - UEL

Londrina/PR - Brasil

tania_geografia@yahoo.com.br

Léia Aparecida Veiga

Doutoranda, Programa de Pós-Graduação em Geografia da Universidade Estadual de Maringá- UEM

Maringá/PR - Brasil

lveiga.geo@gmail.com

Artigo recebido em 17/04/2011 e aceito para publicação em 26/08/2011.

RESUMO: $\quad$ o objetivo do presente trabalho é discutir papéis das pequenas cidades brasileiras no que diz respeito ao processo de especialização funcional. O recorte espacial é a rede urbana norte-paranaense a partir da década de 1970, quando inúmeras transformações de ordem econômico-social incidiram na rede urbana, e de forma singular em algumas pequenas cidades, provocando alterações em seus papéis, como no caso da cidade de Santa Fé. Por intermédio de iniciativas locais, agentes sociais em meio às transformações na agropecuária norte-paranaense concretizaram possibilidades emanadas do todo na forma de prestação de serviços especializados em fotografias e filmes de formaturas em Santa Fé- PR. Com gênese em 1980, foi instalado o primeiro estabelecimento cuja lucratividade dessa empresa criou a perspectiva de implantação de novos estabelecimentos do ramo, seja por ex-funcionários, ex-sócios ou por outros agentes sociais locais oriundos de outras atividades econômicas após a década de 1980. Em 2010 a cidade possuía 48 estabelecimentos especializados em fotografias e filmes de formaturas. Essa especialização funcional na pequena cidade de Santa Fé, complexifica sua inserção na rede urbana norte - paranaense, bem como em outras redes, cujas interações espaciais tornaram-se amplas mediante a instalação de filiais e franquias em vários estados brasileiros.

Palavras-chave: Pequena cidade. Rede urbana. Especialização. Serviços fotográficos.

ABSTRACT: The aim of this paper is to discuss roles of small Brazilian cities with regard to the process of functional specialization. The spatial area is the northern of Parana urban network from the 1970s, when many changes economical and social changes they conducted theselves on the network uniquely in some small cities, causing changes in their roles, as in the city of Santa Fe. Through local initiatives, social workers amid the changes in the agricultural of the north of Parana realized possibilities emanating from the whole in order to provide specialized services for graduations photos and movies with its genesis in 1980 when it was installed the first settlement. The profitability of that company first installed in the city raised the prospect of deploying new business establishments or by former employees or former partners or by 
other social sites from other economic activities after the 1980s. In 2010 the city had 48 specialized in photographs and films of graduations. This functional specialization in the small city of Santa Fe, complicates their integration into the north of Parana urban network, as well as on other networks, whose spatial interactions become large through the installation of branches franchises in various Brazilian states.

Keywords: Small city. Urban network. Specialization. Photographic services.

\section{INTRODUÇÃO}

O objetivo do presente trabalho é discutir papéis das pequenas cidades brasileiras no que diz respeito ao processo de especialização funcional. Trata-se de uma temática ainda pouco estudada, mas importante no sentido de tornar mais inteligível os aspectos das profundas mudanças na urbanização brasileira nas últimas décadas do século XX e início do XXI. Discutir a especialização de pequenos núcleos urbanos põe em evidencia aspectos de multifacetados processos econômicos, sociais, políticos, etc. como a desconcentração da indústria; a ampliação e diversificação dos complexos agroindustriais e sua articulação com a concentração fundiária, a introdução de novos produtos, a estrutura financeira de controle da produção; a ação do poder público na esfera municipal e suas articulações com outras esferas; processos de acirramento do confronto entre capital e trabalho, dentre outros. Desta maneira, além de identificar o aparecimento de novas ou expansão de anteriores atividades, busca-se entender os complexos caminhos de sua realização e articulações diversas mediante especialização produtiva. Inicialmente, o texto discute o sentido de pequenas cidades no contexto atual da urbanização brasileira. Na sequência discute-se o sentido da especialização funcional em pequenas cidades, vinculada dentre outros, a potencialidades latentes que foram alçadas à sua realização mediante ação de grupos locais que valorizaram determinadas localizações e os núcleos urbanos passaram a ser inseridos em diferentes redes. Por último, aborda-se a gênese do setor de serviços fotográficos em Santa Fé - PR, discutindo os percursos para a realização da especialização funcional. Trata-se de um caminho ao entendimento das desiguais espaço-temporalidades da realização de transformações gerais e das diferentes possibilidades de inserção das pequenas cidades na divisão territorial do trabalho.

\section{PEQUENAS CIDADES: EM BUSCA DO CON- CEITO}

O interesse pelas discussões em torno das pequenas cidades vem ganhando mais espaço na bibliografia geográfica brasileira e internacional, advindas de preocupações com este escalão urbano. Esta preocupação pode ser expressa em Bell e Jayne (2009), que propõem uma agenda de investigação sobre pequenas cidades e ressaltam que as mesmas foram ignoradas pelos teóricos urbanos, que na busca de interpretações e proposições de modelos sobre as transformações urbanas, o realizaram a partir da grande cidade e das metrópoles. Evidente que estas exemplificam melhor os principais temas de estudos urbanos, mediante sua complexidade. Posição esta também entendida por Fresca (2001) que ao discutir pequenas cidades no ensino de geografia ressalta que as abordagens e análises do nível metropolitano são fundamentais, mas sobre as pequenas também, como forma de não homogeneizar o espaço, que por sua natureza é socialmente heterogêneo e diferenciado. Neste sentido, ao mesmo tempo em que as teorias sobre o urbano mais complexo "iluminam", podem obscurecer a análise das pequenas cidades, posto que teorias realizadas numa dada escala não podem ser transpostas para outras (BELL; JAYNE, 2009). Outro trabalho recente sobre este escalão urbano foi realizado por Capel (2009) que ao discutir as pequenas cidades na urbanização generalizada e ante a crise global, chama a atenção para a enorme diversidade de situações na Europa. Destacam-se na sua análise os caminhos que vem sendo buscados e implantados em direção à outra valorização das mesmas no contexto europeu. Na contrapartida, McCann (2004) ao discutir as relações entre urbanização e globalização o faz além das chamadas cidades "globais", afirmando que a polarização dos estudos urbanos entre as cidades globais e as supostamente não globais é problemático e que a 
literatura geográfica sobre escala, local e desenvolvimento desigual oferece uma visão mais complexa para a análise atual do urbano. Utilizando-se das noções de multiplexidade e co-presença, fornece uma perspectiva sobre lugares não globais na medida em que enfatiza tanto as singularidades como as interconexões dos lugares de todos os tamanhos, e particularmente como são remodeladas por processos globais de desenvolvimento desigual. Neste caso, o enfoque não é voltado para as pequenas cidades, mas para análises que ultrapassem as análises hegemônicas apoiadas na globalização e suas poderosas representações.

Chama a atenção a análise de Damiani (2006) que ao discutir cidades médias e pequenas no processo de globalização, utiliza-se da relação centro-periferia em que a última é entendida como espaços da repetição de processos, afirmando ainda que as pequenas e médias cidades modificam suas centralidades em termos de processos econômicos, culturais, mas subordinadas, tendo em vista que o núcleo formador está alhures. Corrêa (1999), ao discutir as pequenas cidades na etapa da globalização, também aborda as diversas possibilidades de suas novas inserções em redes urbanas regionais brasileiras, construindo um quadro referencial analítico para as transformações que afetam as pequenas cidades, originadas da globalização.

No entanto, não há no Brasil um conceito que possa ser considerado o mais abrangente e menos isento de críticas, posto que esteja fortemente carregado de sentidos, tanto intelectuais como de senso comum. Porém, ao utilizar-se o termo pequena cidade isto não significa considerá-la pequena apenas por possuir um reduzido número de habitantes. Aceitar apenas um número para considerá-las como grandes, médias ou pequenas conduziria a uma interpretação equivocada, devido à generalização de núcleos que, apesar de possuírem um contingente populacional quantitativamente semelhante, são diferentes em sua gênese e dinâmica econômico-social (FRESCA, 2001). Nas palavras de Santos (1986, p. 69-70), há que se levar em consideração que o "[...] fenômeno urbano abordado de um ponto de vista funcional, é antes um fenômeno qualitativo e apresenta certos aspectos morfológicos próprios a cada civilização [...]".

Para o referido autor, pensar uma aglomeração enquanto uma cidade em seu nível mais fundamental significa aceitar que existe no interior da mesma "[...] um limite mínimo de complexidade das atividades urbanas capazes, em um momento dado, de garantir ao mesmo tempo um crescimento auto-sustentado e um domínio territorial [...]" (SANTOS, 1982, p.70). Em outras palavras, uma aglomeração pode ser entendida enquanto uma cidade a partir do momento que a mesma passa a desenvolver atividades que não são agrícolas, mas sim vinculadas ao comércio e a prestação de serviços. Atividades essas que atendem às necessidades de sua população (urbana e rural) ao mesmo tempo em que viabilizam a circulação e distribuição da produção local e regional, garantindo assim à cidade um domínio territorial. Diante disso, pode-se afirmar que uma aglomeração torna-se cidade quando " [...] deixa de servir às necessidades da atividade primária para servir às necessidades inadiáveis da população, com verdadeira especialização do espaço" (SANTOS, 1982, p.71).

A partir das idéias do autor supracitado, pode-se entender que existe uma dimensão mínima para que uma aglomeração seja considerada como uma cidade de fato, dimensão esta que reside na capacidade que a mesma terá de satisfazer "[...] as necessidades vitais mínimas reais ou criadas de toda uma população, função essa que implica em uma vida de relações [...]" (SANTOS, 1982, p.71). Note-se bem que o autor está analisando o mais baixo escalão urbano, isto é, aquelas cidades de menor complexidade funcional em termos de oferta de bens e serviços e de área de influência, além é claro, de reduzida população.

No entanto, para Fresca (2001) dentro do que se tem denominado de pequenas cidades " [...] vamos encontrar desde aquelas com limite mínimo da complexidade de atividades urbanas até aquelas donde tal complexidade é bastante acentuada, refletindo inclusive, diferenças do ponto de vista populacional [...]" (FRESCA, 2001, p. 28), demonstrando a variedade de condições e elementos que caracterizam essas cidades.

Destarte, pautando-se na perspectiva de Santos (1982), Corrêa (1989) e Fresca (1990, 2001, 2004), acredita-se que o caminho para a análise e caracterização de uma cidade como sendo pequena, seria a compreensão de sua inserção numa dada área, região ou rede urbana, entendimento esse que deve 
estar correlacionado à formação econômica social. Neste sentido, Corrêa (2009) coloca que a pequena cidade pode ser melhor definida a partir do nível de centralidade, isto é, das relações econômicas que um dado núcleo urbano estabelece em dada área a partir da oferta de bens e serviços, com correspondente domínio territorial, podendo-se fazer presentes nesta área, cidades menores ainda, vilas e povoados. Para o autor, as pequenas cidades correspondem a centros locais em termos de oferta de bens e serviços - lugares centrais - podendo apresentar adicionalmente outras funções. Embora outros elementos sejam constituintes para o conceito de pequenas cidades como ser sede político-administrativa, poder de gestão do território, o fato é que à mesma, acresce-se a oferta de bens e serviços. Reside aí o reforço que por da mesma a conceituação de pequenas cidades, o grau de centralidade do mesmo seja o mais profícuo.

\section{ESPECIALIZAÇÃO PRODUTIVA}

A temática sobre a especialização produtiva em cidades de diversos tamanhos e complexidades apresenta relativa bibliografia na literatura geográfica. No entanto, a discussão entre esta temática e pequenas cidades não tem sido explorada, dificultando em parte análise das múltiplas e complexas relações entre o avanço da urbanização a produção, distribuição, circulação e consumo.

As transformações da urbanização brasileira desde últimas décadas do século XX colocaram em relevo algumas questões que passaram a afetar de modo mais intenso as pequenas cidades. Dentre estas, tem-se outra etapa da desconcentração industrial a partir das metrópoles e que, na lógica capitalista de maximizar os lucros e articuladas a diferentes fatores locacionais, acabaram por encontrar em pequenas cidades uma das localizações viáveis para sua realização.

Para Fresca (2002, p. 17) na medida em que processos gerais incidiram em redes urbanas regionais, como a norte-paranaense, uma das possibilidades de realização dos mesmos, foi a "[...] criação de uma heterogeneidade que antes não estava presente e onde o que mais se ressalta é a continuidade da diferenciação e redefinição dos lugares [...]". Articulada à complexificação da divisão territorial do trabalho tem-se caminhos teóricos para o entendimento de que as pequenas cidades podem ser refuncionalizadas; desenvolvendo especializações produtivas, sejam elas oriundas de investimentos locais e regionais ou pode ainda vincular-se a investimentos extra-regionais. Vinculado a esta construção analítica, a especialização produtiva precisa ser analisada à luz das implicações que a mesma provoca na pequena cidade. Em outras palavras, em uma pequena cidade a especialização assume várias possibilidades como ser a maior geradora de empregos locais; a maior geradora de impostos municipais; sem que para tal a amplitude produtiva a coloque como importante controladora do mercado nacional ou regional. É o que ocorre com Santo Antonio do Sudoeste, localizada no extremo sudoeste do Paraná, especializada na indústria confeccionista, mas que não tem produção expressiva no contexto regional ou nacional. Por outro lado, a especialização pode assumir volumes produtivos que coloca a pequena cidade como a responsável por parcela significativa da produção nacional e regional. É o que ocorreu com as pequenas cidades de Loanda e Jaguapitã: a primeira, com cerca de 16 mil habitantes localizada no noroeste do Paraná e especializada na produção de metais sanitários, controlava cerca de $15 \%$ da produção nacional segundo (FRESCA, 2009); a segunda, com 12.256 habitantes (IBGE, 2010) localizada no norte do Paraná e especializada na produção industrial de mesas para bilhar, controlava aproximadamente $30 \%$ da produção nacional de acordo com (VEIGA, 2007). Essa diversidade de situações correlaciona-se a diferentes caminhos de singularização de processos gerais.

\section{ESPECIALIZAÇÃO EM SERVIÇOS FOTOGRÁ- FICOS: O CASO DE SANTA FÉ}

Diferentemente de outras pequenas cidades que em meio às transformações na agropecuária norte-paranaense a partir do final da década de 1970, especializaram-se na produção industrial de determinado produto, Santa Fé, inserida na rede urbana norte-paranaense, com aproximadamente 10.410 habitantes (IBGE, 2010), vem se destacando nas últimas décadas pela oferta de serviços fotográficos para formaturas. No ano de 2009 o setor de serviços respondeu por cerca de $61,32 \%$ do Produto Interno 
Bruto municipal, com destaque para as empresas de fotografias, enquanto a agricultura participava com $31,5 \%$ e a indústria representava $7,34 \%$ do PIB (O DIÁRIO DE MARINGÁ, 2009).

De acordo com levantamento de campo junto a Associação das Empresas de Fotografia de Santa
Fé - PR, estavam cadastradas em 2010, cerca de 40 empresas do ramo, número este semelhante àqueles disponibilizados pela Prefeitura Municipal, conforme pode ser observado na Tabela 01 a seguir.

Tabela 01: Número de estabelecimentos comerciais, industriais e prestadores de serviços cadastrados na prefeitura municipal de Santa Fé - PR: 2010

\begin{tabular}{|c|c|}
\hline \multicolumn{2}{|l|}{ Comércio Varejista } \\
\hline artigos fotográficos, cinematográficos e formaturas & 03 \\
\hline artigos diversos & 144 \\
\hline \multicolumn{2}{|l|}{ Comércio Atacadista } \\
\hline produtos hortifrutigranjeiros & 01 \\
\hline \multicolumn{2}{|l|}{ Estabelecimentos industriais } \\
\hline Fabricação de peças do vestuário & 19 \\
\hline Fabricação de alimentos & 13 \\
\hline Fabricação de produtos diversos & 22 \\
\hline $\begin{array}{l}\text { Fabricação de embalagens de madeira, estojo para álbuns fotográficos, DVDs e } \\
\text { álbuns fotográficos }\end{array}$ & 02 \\
\hline \multicolumn{2}{|l|}{ Prestação de Serviços } \\
\hline $\begin{array}{l}\text { cobertura fotográfica e filmagem de festas e eventos + comércio varejista de } \\
\text { artigos fotográficos e cinematográficos + laboratório fotográfico + locação de } \\
\text { artigos do vestuário e complementos para formatura }\end{array}$ & 48 \\
\hline $\begin{array}{l}\text { transportes coletivos de passageiros, transporte rodoviário de passageiros (urbanos } \\
\text { e não urbanos) e agencia de vendas de passagens }\end{array}$ & 10 \\
\hline $\begin{array}{l}\text { manutenção de veículos e outros (funilaria, pintura, manutenção e reparação } \\
\text { mecânica), lavagem e lubrificação de veículos e afins; locaçâo de veículos }\end{array}$ & 21 \\
\hline $\begin{array}{l}\text { reparação e manutenção de equipamentos eletroeletrônicos de uso pessoal e } \\
\text { doméstico, de eletrodomésticos, de máquinas e aparelhos em geral, de informática } \\
\text { em geral; equipamentos de comunicação (diversos) }\end{array}$ & 28 \\
\hline comunicação, publicidade 1 & \\
\hline transporte de cargas em geral, de terraplenagem & 10 \\
\hline saúde & 10 \\
\hline financeiros, contábeis e advogado, jurista, mag. Prom. ou assemelhado & 14 \\
\hline diversos & 57 \\
\hline
\end{tabular}

Org.: VEIGA, L. A.

Fonte: Prefeitura Municipal de Santa Fé/PR, ago. 2010

A Tabela 01 evidencia a expressividade numérica do setor de serviços na cidade de Santa Fé, com destaque para os estabelecimentos de fotografia, que perfaziam o total de 48 estabelecimentos em 2010. Além dos estabelecimentos prestadores de serviços, há que se chamar a atenção também para a presença de dois estabelecimentos que comercializavam artigos fotográficos, cinematográficos e formaturas no varejo, bem como para as duas fábricas responsáveis pela produção de embalagens de madeira para álbuns fofográficos e DVDs e embalagens plásticas para os mesmos produtos. Ressalta-se que, numericamente, esses estabelecimentos comerciais e industriais relacionados à fotografia não eram expressivos até 2010, no entanto, os mesmos podem 
ser entendidos como uma possibilidade de investimento local correlacionado diretamente aos serviços de fotografias.

As empresas de serviços fotográficos cadastradas na Prefeitura Municipal, geravam em 2010, aproximadamente 400 empregos diretos e indiretamente empregavam inúmeros representantes comerciais e fotógrafos que atuavam em diversos estados brasileiros. Estima-se que cerca de $10 \%$ da população urbana estava ocupada com trabalhos fotográficos de formaturas e filmes no referido ano (Levantamento de campo, jun. 2010).

A gênese desse tipo de serviço na cidade ocorreu no início dos anos de 1980, mediante ação de Vanderlei Kello Francisco Ferreira que, a partir de modestos recursos, instalou seu estúdio denominado Cine Foto Kello e iniciou a atividade fotografando casamentos, batizados e aniversários.

Naquele momento os equipamentos iniciais eram compostos por 01 máquina fotográfica (Canon FTB), 01 laboratório preto e branco, 01 estúdio fotográfico com lâmpadas e 01 vitrine para amostra de fotos, para a qual contava com um empregado. Em 1982 havia 03 funcionários e em 1983, o quadro de funcionários fora ampliado para 07 (Levantamento de campo, jun. 2010).

Nos primeiros anos de atuação o proprietário realizava propagandas de seu estúdio em cidades próximas a Santa Fé, como Nossa Senhora das Graças, Lobato, Guaraci, Atalaia, Flórida e Munhoz de Mello, deixando nestas cidades cartazes sobre os serviços prestados em cartórios e escolas. Também estabelecia contatos com grupos responsáveis pela organização de eventos e festas com o objetivo de fotografar rodeios, quermesses, festas religiosas, etc. Entre 1986 a 1988 foi alterada a estrutura da empresa mediante o ingresso de dois irmãos na sociedade e os proprietários começaram a investir na expansão da empresa, iniciando em 1988, os eventos de formatura e baile de debutantes. A sociedade foi desfeita em 1998, quando cada irmão passou a ter sua própria empresa de fotografia.

A empresa Kello expandiu seu raio de atuação, conquistando mercado consumidor em outros estados brasileiros como pode ser observado na Figura 01. Segundo levantamento de campo em junho de 2010, além da matriz em Santa Fé, o grupo possuía filiais e/ ou franquias em cidades dos estados de Minas Gerais, Rio de Janeiro, Bahia, Espírito Santo, Goiás, Mato Grosso, Mato Grosso do Sul e Amazonas. O número de funcionários também foi ampliado, atingindo cerca de 300 funcionários no ano de 2010, dos quais $50 \%$ atuava em serviços administrativos, financeiros e de produção (processamento de fotos e montagem de álbuns) e os demais atuavam como fotógrafos, cinegrafistas, vendedores e representantes comerciais.

De acordo com o proprietário, todo o lucro obtido nos últimos 30 anos foi reinvestido na expansão da própria empresa, através de aquisição de novos equipamentos, sistemas de inovação de produtos e gestão, bem como na capacitação de funcionários. Em relação a este último aspecto, funcionários têm participado sistematicamente de feiras gráficas e de fotografia na Alemanha e nos Estados Unidos. Investimentos também têm sido feitos na aquisição de equipamentos de última geração, o que possibilitou a instalação de laboratórios profissionais digitais específicos para a impressão de arquivos digitais dos mais diversos tamanhos.

Figura 01: Localização das empresas prestadoras de serviços fotográficos com sede em Santa Fé (PR) e filiais/franquias nos demais estados brasileiros.

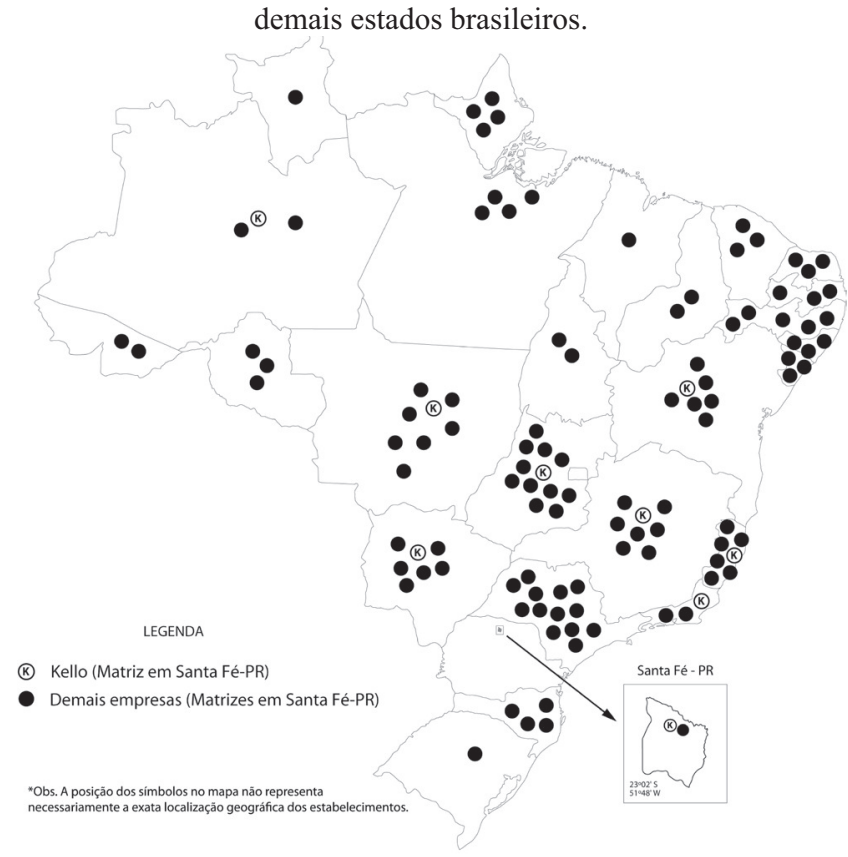

Org.: VEIGA, L. A.

Fonte: Levantamentos de Campo, jun. 2010. 
Em relação ao mercado consumidor, além do grupo Kello, (Figura 01) também podemos observar as filiais e/ou franquias de outros estabelecimentos prestadores de serviços de fotografia que possuem matrizes instaladas em Santa Fé - PR. Em outros termos, além da empresa pioneira, outras 24 expandiram seu raio de atuação conquistando também mercado consumidor em outros estados brasileiros como pode ser observado no Quadro 01.

Em se tratando do mercado consumidor, dentre as 25 empresas de serviços em fotografia, o grupo
Kello precursor dessa atividade na cidade de Santa Fé - PR, detinha filiais e/ou franquias em 08 estados brasileiros além do Paraná, ocupando em 2010 a quinta posição. A primeira empresa identificada (quadro 01) teve acesso ao maior número de estados em 2010, cerca de 21, além do Paraná, estando presente em todas as Regiões brasileiras por meio de filiais e/ou franquias, conquistando assim mercado consumidor maior que os demais estabelecimentos de serviços em fotografia de Santa Fé - PR.

Quadro 01: Empresas prestadoras de serviços fotográficos segundo a quantidade de filiais/franquias no Brasil.

\begin{tabular}{|c|c|c|c|c|c|c|c|c|c|c|c|c|c|c|c|c|c|c|c|c|c|c|c|c|c|c|}
\hline \multirow{2}{*}{ Empresas } & \multicolumn{7}{|c|}{ Norte } & \multicolumn{3}{|c|}{ Centro-Oeste } & \multicolumn{9}{|c|}{ Nordeste } & \multicolumn{4}{|c|}{ Sudeste } & \multicolumn{3}{|c|}{ Sul } \\
\hline & RR & AP & AM & $\mathrm{AC}$ & RO & PA & TO & GO & MT & MS & MA & PI & $\mathrm{CE}$ & RN & PB & PE & $\mathrm{AL}$ & $\mathrm{SE}$ & BA & $\mathrm{MG}$ & ES & RJ & SP & PR & \begin{tabular}{l|l} 
SC \\
\end{tabular} & RS \\
\hline 01 & a & a & " & a & & I. & a & a & घ & a & a & a & a & 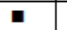 & a & . & ! & . & & a & & & घ & $\bullet$ & ! & . \\
\hline 02 & & . & I & . & . & I & & & ! & . & & ! & ! & - & I & I & I & I & I & I & . & . & I & $\bullet$ & I & \\
\hline 03 & & & & & & & & ! & $\square$ & $\square$ & & & . & . & . & $\square$ & ! & . & . & . & & & ! & $\bullet$ & & \\
\hline 04 & & & & & & & & - & - & - & & & & & & - & & & - & - & . & . & - & $\bullet$ & . & \\
\hline 05 Kello* & & & घ & & & & & - & - & - & & & & & & & & & - & - & - & ! & & $\bullet$ & & \\
\hline 06 & & & & & . & & & - & - & - & & & & & & & & & - & - & - & & I & $\bullet$ & & \\
\hline 07 & & & & & & & & . & - & - & & & & & & & & & - & - & - & & - & $\bullet$ & & \\
\hline 08 & & . & & & & . & & & & & & & & & & & & & & & & & & $\bullet$ & & \\
\hline 09 & & - & & & & ! & & & & & & & & & & & & & & & & & & $\bullet$ & & \\
\hline 10 & & & & & & & & - & & & & & & & & & & & & & - & & & $\bullet$ & & \\
\hline 11 & & & & & & & & - & & & & & & & & & & & & & & & . & $\bullet$ & & \\
\hline 12 & & & & & & & & - & - & & & & & & & & & & & & & & & $\bullet$ & & \\
\hline 13 & & & & & & & & - & & & & & & & & & & & & & & & - & $\bullet$ & & \\
\hline 14 & & & & & . & . & & & & & & & & & & & & & & & & & & $\bullet$ & & \\
\hline 15 & & & & & & & & & & & & & & & & & & & & & & & $\square$ & $\bullet$ & & \\
\hline 16 & & & & & & & & & & & & & & & & & & & & & & & ! & $\bullet$ & & \\
\hline 17 & & & & & & & & ! & & & & & & & & & & & & & & & & $\bullet$ & & \\
\hline 18 & & & & & & & & & & & & & & & & & & & & & & & & $\bullet$ & $\square$ & \\
\hline 19 & & & & & & & & & & & & & & & & - & & & & & & & & $\bullet$ & & \\
\hline 20 & & & & & & & & & & & & & & & & & & & & & & & ! & $\bullet$ & & \\
\hline 21 & & & & & & & & & & & & & & & & & & & & & - & & & $\bullet$ & & \\
\hline 22 & & & & & & & & & & & & & & & & & & & & & & & - & $\bullet$ & & \\
\hline 23 & & & & & & & & & & & & & & & & & & & & - & & & & $\bullet$ & & \\
\hline 24 & & & & & & & & . & & & & & & & & & & & & & & & & $\bullet$ & & \\
\hline 25 & & & & & & & & & & & & & & & & & & & & & & & \begin{tabular}{|l|}
. \\
\end{tabular} & $\bullet$ & & \\
\hline \multicolumn{27}{|c|}{ - Filiais e/ou franquias em outros estados / • Matriz instalada em Santa Fé - PR. * Somente o proprietário da Kello autorizou a divulgação do nome } \\
\hline
\end{tabular}

Quanto à gênese das demais empresas, é importante colocar que a partir da instalação e expansão do grupo Kello, outros agentes sociais locais, ao perceberem a expansão da empresa (ampliação física, investimento em equipamentos e capacitação de funcionários) e a ampliação do mercado consumidor, ou seja, a visível lucratividade da primeira empresa, os mesmos passaram a investir na criação de outros estabelecimentos prestadores de serviços em fotografias. Ressalta-se que parte desses agentes sociais, até aquele momento, atuava em outros setores da economia, enquanto que a outra parte já atuava no ramo de fotografia, seja como funcionário, seja na condição de sócio. Um exemplo é o da empresa Moris Formaturas, cujos proprietários foram vendedores da Kello.

No caso destes estabelecimentos, chama-se a atenção para a idéia de contato próximo, considerado um processo importante na expansão de atividades, em sua maioria, econômicas. Este processo, explicado por Fresca (2000), refere-se a expansão numérica de empresas do mesmo ramo em uma dada cidade, mediante ação de ex-empregados e/ou ex-sócios do ramo de fotografias, bem como do ingresso de pessoas de diversos setores produtivos (muitas vezes sem ligação 
direta com a atividade), que observando ascensão social dos proprietários, acabam por investir na mesma atividade. Nas palavras de Fresca (2000, p.361) "[...] a partir do sucesso de uma empresa, gerou-se a perspectiva da implantação de outras, sem que para tal, tenha havido uma política ou ações coordenadas por parte de órgãos ou agentes privados como forma de fomentar a criação [...]" desses estabelecimentos. Nesse contexto, pode-se dizer que a primeira empresa instalada por Vanderlei Kello Francisco Ferreira foi precursora, pelo fato "[...] que desta [...] emergiram outras, seja pela criação da sociedade e quando de seu rompimento, um dos ex-sócios abriu nova empresa; e principalmente, seja pela experiência gerada aos funcionários que depois iniciaram atividades" (FRESCA, 2005, p.55-59) no ramo da fotografia. Tal processo permitiu a ampliação do número de estabelecimentos que estavam atuando, até o ano de 2010, no ramo de fotografias na pequena cidade de Santa Fé, tornando essa pequena cidade especializada.

\section{CONSIDERAÇÕES FINAIS}

A pequena cidade de Santa Fé, assim considerada pelo fato de colocar-se com um nível de centralidade muito fraco na rede urbana norte-paranaense, por intermédio de diversos processos, acabou por tornar-se especializada em serviço fotográfico

O setor de prestação de serviço especializado em fotografias, principalmente de formaturas, com gênese em 1980, surgiu a partir de iniciativas de agentes sociais locais que com parcos capitais, iniciaram a atividade em instalações modestas, com poucos equipamentos e alguns funcionários. A expansão do número de unidades desse ramo nas décadas seguintes ocorreu da mesma forma, sempre correlacionada às iniciativas locais.

O desenvolvimento e a consolidação deste setor prestador de serviços, acabou por atribuir novo papel a Santa Fé na divisão territorial do trabalho e na rede urbana norte - paranaense, pois além de ser um centro local com funções urbanas voltadas ao atendimento da produção e da população do campo, acumula condição de ser um centro urbano especializado em serviços de fotografias e filmes de formaturas após década de 1990. Mesmo que tal processo não tenha alterado sua condição como cidade com nível muito fraco de centralidade (FRESCA, 2000), essa especialização propiciou à cidade, interações espaciais com outras redes urbanas no âmbito nacional, ampliando significativamente as interações espaciais mediante a instalação de filiais e/ou franquias em cidades de diferentes estados brasileiros, conquistando assim significativa porção do mercado consumidor nacional.

Isso significa que o entendimento da rede urbana e a reinserção dos núcleos urbanos passou a ser cada vez mais complexa, pois "[...] à medida que se instaura novas etapas da produção, circulação, distribuição e consumo com inserção específica para cada rede e cidade, a diferenciação torna-se maior entre as primeiras e entre as seguintes" (FRESCA, 2002, p.7).

Assim, podemos caracterizar a rede urbana norte - paranaense com sendo uma rede com forte complexidade e diversidade, correlacionada tanto a sua inserção na divisão territorial do trabalho como em seus núcleos urbanos. Esse caminho explicitado por Fresca (2002) permite-nos compreender como Santa Fé, mediatizada por agentes sociais diversos, foi capaz de perceber a possibilidade de realização de um dos processos universais, singularizada na oferta de serviços especializados em fotografias e filmes de formaturas.

\section{REFERÊNCIAS}

BELL, D.; JAYNE, M. Small Cities? towards a research agenda. International Journal of Urban and Regional Research, Oxford, v. 33, n. 3, p. 683-699, 2009.

CAPEL, H. Las pequeñas ciudades en la urbanización generalizaday ante la crisis global. Investigaciones $G e-$ ográficas, Boletín del Instituto de Geografía, UNAM, v. 70, p. 7-32, 2009.

CORRÊA, R. L. Globalização e reestruturação da rede urbana: uma nota sobre as pequenas cidades. Território, Rio de Janeiro, v. 4, n. 6, p. 43-52. 1999. 
, R. L. As pequenas cidades na confluência do urbano e do rural. Texto apresentando na mesa redonda do II Simpósio sobre pequenas cidades. Rio de Janeiro, 2009. Inédito.

DAMIANI, Amélia Luisa. Cidades médias e pequenas no processo de globalização: apontamentos bibliográficos. In. LEMOS, A. I. G.; ARROYO, M. SILVEIRA, M. L. (Org). América Latina: cidade, campo e turismo. San Pablo: CLACSO, 2006. Consejo Latinoamericano de Ciencias Sociales.

IBGE. Censo Demográfico - Paraná. 2010. Disponível em: http://www.ibge.gov.br/home/ estatistica/populacao/ censo2010/resultados_dou/default_resultados_dou.shtm. Acesso em: 06 mar. 2011.

FRESCA, T. M. A dinâmica funcional da rede urbana do oeste paulista estudo de casos: Osvaldo Cruz e Inúbia Paulista. 1990. 282 f. Dissertação (Mestrado em Geografia) -Universidade Federal de Santa Catarina, Florianópolis. 1990.

- Transformações da rede urbana do norte do Paraná: estudo comparativo de três centros. 2000. $432 \mathrm{f}$. Tese (Doutorado em Geografia) - Universidade Estadual de São Paulo, São Paulo, 2000.

Em defesa dos estudos das cidades pequenas no ensino de geografia. Geografia, Londrina, v.10, n.01, p. 27-34, 2001.

A rede urbana norte paranaense: de um padrão tipo christalleriano a uma condição de diversidade e complexidade. In: FRESCA, T. M. SALVI, R. F. ;ARCHEIA, R. S. (Org.) Dimensões do espaço paranaense. Londrina: EDUEL, 2002. p. 1-28
A rede urbana do norte do Paraná. Londrina: EDUEL, 2004. 403 p.

. A rede urbana norte-paranaense e cidades especializadas em produções industriais: Arapongas, Apucarana e Cianorte. In: ENCONTRO DE GEÓGRAFOS DA AMÉRICA LATINA, 10, 2005, São Paulo. Anais... São Paulo, 2005, p. 54-74.

Redefinição dos papéis das pequenas cidades na rede urbana do norte do Paraná. In: ENDLICH, A. M.; ROCHA, M. M. Pequenas cidades e desenvolvimento local. Maringá: PGE, 2009. p. 41-68.

O DIÁRIO DE MARINGÁ. Uma cidade movida a fotografia de eventos, Maringá, 12 ago. 2009. Disponível em: http://maringa.odiario.com/parana/noticia/223422/ uma-cidade-movida-a-fotografia-de-eventos/. Acesso em: 11 jun. 2010.

SANTOS, M. Espaço e sociedade: ensaios. Petrópolis: Vozes, 1982. $152 \mathrm{p}$.

Pensando o espaço do homem. São Paulo: Hucitec, 1986. 60 p.

VEIGA, L. A. Jaguapitã-PR: pequena cidade da rede urbana norte- paranaense especializada na produção industrial de mesas para bilhar. 2007. 220 f. Dissertação (Mestrado em Geografia Meio Ambiente e Desenvolvimento) - Universidade Estadual de Londrina. Londrina - PR, 2007.

Soc. \& Nat., Uberlândia, ano 23 n. 3, 387-396, set/dez. 2011 
